\title{
Morfometria de frutos e sementes e germinação de carobinha (Jacaranda decurrens subsp. symmetrifoliolata Farias \& Proença), após o armazenamento
}

\author{
SANGALLI, A. ${ }^{1 *}$; VIEIRA, M.C. ${ }^{2}$; SCALON, S.P.Q. ${ }^{2}$; ZÁRATE, N.A.H. ${ }^{2}$; SILVA, C.B. ${ }^{3}$; RIBEIRO, I.S. ${ }^{4}$ \\ ${ }^{1}$ Faculdade de Ciências Biológicas e Ambientais, Universidade Federal da Grande Dourados-UFGD, Caixa Postal \\ 322, CEP: 79.804-970, Dourados-Brasil *andreiasangalli@ufgd.edu.br ${ }^{2}$ Faculdade de Ciências Agrárias, UFGD. \\ ${ }^{3}$ Programa Pós Graduação - Mestrado em Biologia, UFMS, CEP: 79070-900, Campo Grande-Brasil ${ }^{4}$ Programa de \\ Pós Graduação - Mestrado em Produção Vegetal, FCA, UFGD, CEP: 79.804-970, Dourados-Brasil
}

\begin{abstract}
RESUMO: O trabalho teve como objetivos avaliar a morfometria dos frutos e sementes de carobinha (Jacaranda decurrens subsp. symmetrifoliolata) e o efeito de temperaturas na germinação de sementes armazenadas em ambiente sem controle de temperatura e umidade relativa. $O$ estudo foi realizado no Laboratório de Sementes da UFGD, Dourados, MS. Em amostra de 120 frutos e de 550 sementes foi determinado: o comprimento, a largura, a espessura, o número de sementes por fruto, e a massa dos frutos. A germinação foi estudada após três períodos de armazenamento das sementes (120, 480 e 720 dias) a temperatura ambiente e sob quatro temperaturas de germinação: três constantes $\left(18,25\right.$ e $\left.30^{\circ} \mathrm{C}\right)$ com luz contínua e sob condição de tempera alternada, $20-30^{\circ} \mathrm{C}$, com fotoperíodo de 12 horas. O delineamento experimental foi inteiramente ao acaso, em arranjo fatorial $3 \times 4$, com quatro repetições. As variações nas medidas de frutos e sementes representam indício da alta variabilidade genética populacional. As sementes armazenadas por 120 dias e submetidas à germinação na temperatura de $25^{\circ} \mathrm{C}$ resultaram em $69,4 \%$ de germinação e índice de velocidade de germinação - IVG, de 0,983. Sob temperaturas de germinação de $30^{\circ} \mathrm{C}$, constante, e de $20-30^{\circ} \mathrm{C}$, alternada, obtiveram-se $63,9 \%$ e $63,8 \%$ de germinação e 0,486 e 0,413 de IVG, respectivamente. Sob temperatura de $18^{\circ} \mathrm{C}$ a germinação foi lenta e menor, 27,7\% e IVG de 0,119. As sementes armazenadas por 480 e 720 dias não germinaram. Com base no comportamento fisiológico das sementes é possível classificar Jacaranda decurrens subsp. symmetrifoliolata como espécie intermediária (entre ortodoxa e recaucitrante).
\end{abstract}

Palavras-chave: planta medicinal, Cerrado, biometria de sementes e frutos, germinação

ABSTRACT: Fruit and seed morphometry and germination of "carobinha" (Jacaranda decurrens subsp. symmetrifoliolata) seeds after storage. This study aimed to evaluate the morphometry of fruits and seeds of Jacaranda decurrens subsp. symmetrifoliolata ("carobinha") and the effect of temperature on the germination of seeds that were stored in environment without controlled temperature and relative humidity. The study was carried out at Seed Laboratory of Federal University of Grande Dourados, Mato Grosso do Sul, Brazil. For a sample of 120 fruits and 550 seeds, the following variables were determined: length, width and thickness, besides the number of seeds per fruit and fruit biomass. Germination was studied after three seed storage periods (120, 480 and 720 days) at environment temperature and four germination temperatures: three constant temperatures $\left(18,25\right.$ and $\left.30^{\circ} \mathrm{C}\right)$ with continuous light, and one alternating temperature, $20-30^{\circ} \mathrm{C}$, with 12 -hour photoperiod. Experimental design was completely randomized, in $3 \times 4$ factorial schemes, with four replicates. The variations in the measures of fruits and seeds evidence a high genetic variability in the population. The seeds stored for 120 days and subjected to germination test at $25^{\circ} \mathrm{C}$ resulted in $69.4 \%$ germination and germination velocity index - GVI of 0.983 . At $30^{\circ} \mathrm{C}$, constant temperature, and $20-30^{\circ} \mathrm{C}$, alternating temperature, germination was $63.9 \%$ and $63.8 \%$ while GVI was 0.486 and 0.413 , respectively. At $18^{\circ} \mathrm{C}$, germination was slow and lower, $27.7 \%$, and GVI was 0.119 . Seeds stored for 480 and 720 days did not germinate. Based on the physiological behavior of seeds, it is possible to classify Jacaranda decurrens subsp. symmetrifoliolata as an intermediate species (between orthodox and recalcitrant).

Key words: medicinal plant, Cerrado, seed and fruit biometry, germination

Recebido para publicação em 23/11/2009

Aceito para publicação em 23/01/2012

Rev. Bras. PI. Med., Botucatu, v.14, n.2, p.267-275, 2012. 


\section{INTRODUÇÃO}

O Estado de Mato Grosso do Sul apresenta grande diversidade de vegetação, tais como Cerrados, Matas semidecíduas e Matas de galeria. Os Cerrados cobrem $65 \%$ e as florestas semidecíduas, 8,9\% da área do Estado. Por isso, a intensificação dos estudos sobre plantas nativas é uma etapa essencial para que seja incrementado o conhecimento desse patrimônio natural. Dentre outros, estudos básicos sobre a dormência e a germinação de sementes das espécies desse bioma são fundamentais e pouco realizados (IBGE, 1992; Melo et al., 2008).

Jacaranda decurrens subsp. symmetrifoliolata, Bignoniaceae, é subarbusto xilopodífero, que ocorre exclusivamente na região sudoeste do Estado de Mato Grosso do Sul, em áreas com vegetação de Cerrado a Campo Limpo (Farias \& Proença, 2003).

A importância dos estudos com essa subespécie é justificada pelo uso tradicional do sistema subterrâneo em chás e garrafadas como depurativo do sangue e cicatrizante de feridas uterinas e dos ovários (Sangalli et al., 2002). Outras espécies do gênero também têm sido indicadas no tratamento de diabetes, reumatismo, hipertensão, alergias, prisão de ventre, inflamações e infecções ginecológicas, colesterol, doenças do fígado, sarna, febres e como bioinseticidas, dentre elas J. caroba (Vell.) A. DC., J. cuspidifolia Mart., J. decurrens Cham. (Pott \& Pott, 1994; Schwenk \& Silva, 2000; Pérez, 2002; Nunes et al., 2003; Vila Verde et al., 2003; Rodrigues \& Carvalho, 2007).

Dados de morfometria de frutos e sementes são valiosos em estudos de melhoramento genético de populações, nas padronizações de testes em laboratório e para a otimização na produção de mudas (Ferronato et al., 2000). O conhecimento da morfologia dos frutos e diásporos de dispersão, bem como as características biométricas, fornecem subsídios importantes para a diferenciação de espécies pioneiras e não pioneiras em florestas tropicais (Cruz et al., 2001), para os estudos de sucessão ecológica e regeneração de ecossistemas florestais (Beltrati \& Paoli, 2003) e para as pesquisas com espécies endêmicas, como é o caso da J. decurrens subsp. symmetrifoliolata. Também o armazenamento e a viabilidade das sementes em termos de germinação são parâmetros fundamentais para estudos subseqüentes.

O armazenamento de sementes é constituído por um conjunto de procedimentos voltados à preservação da qualidade do produto mantendo as características físicas, fisiológicas e sanitárias, proporcionando a formação de mudas sadias para plantios comerciais e manutenção de recursos genéticos em bancos de genes de florestas nativas (Aguiar et al., 1993; Floriano, 2004). As espécies se comportam diferentemente em função das condições de armazenamento apresentando exigências próprias para a manutenção da qualidade fisiológica, o que requer estudos específicos. A importância da temperatura e da umidade relativa do ambiente no armazenamento e suas interações são prioritárias para o entendimento das exigências da espécie quanto à manutenção da viabilidade.

Dessa forma, o objetivo do trabalho foi determinar as características biométricas dos frutos e sementes e avaliar o potencial germinativo das sementes de J. decurrens subsp. symmetrifoliolata armazenadas por 120, 480 e 720 dias sob condições ambientes de temperatura e umidade relativa, através do teste de germinação conduzido em diferentes temperaturas.

\section{MATERIAL E MÉTODO}

O trabalho foi conduzido no Laboratório de Botânica, da Faculdade de Ciências Agrárias, da Universidade Federal da Grande Dourados (UFGD). Os frutos de J. decurrens subsp. symmetrifoliolata foram coletados de 20 plantas cultivadas no Horto de Plantas Medicinais da UFGD, em Dourados, a $22^{\circ} 11^{\prime} \mathrm{S}$ e $54 \div 56^{\prime} \mathrm{W}$. As plantas tinham seis anos de idade e foram provenientes de sementes coletadas de várias plantas de área nativa, na Fazenda Lagoa Azul, a 2205'S e 5506'W, na Rodovia BR 270 , Km 70 , Dourados a Itahum, com vegetação característica de Cerrado.

A subespécie foi identificada no Instituto de Biologia, Departamento de Botânica da UNICAMP, utilizando o exemplar tipo R. Farias 52; o parátipo encontra-se no herbário da UNICAMP (UEC) W.G. Garcia 14.008.

\section{Morfometria dos frutos e sementes}

O estudo morfométrico foi realizado em frutos coletados em fevereiro de 2007, utilizando a metodologia relatada por Barroso et al. (1999) e Souza (2003). A prancha representando a espécie foi confeccionada com o auxílio de câmara clara.

Em uma população de 25 plantas foram colhidos, aleatoriamente, 120 frutos, usando como índice de colheita o início do amarelecimento dos mesmos. As massas foram determinadas em balança de precisão enquanto o comprimento, a largura e a espessura foram medidos com paquímetro digital. Após a secagem e a abertura dos frutos foi contado o número de sementes por fruto.

Para a análise morfométrica as sementes foram retiradas dos frutos e misturadas aleatoriamente, independentemente da coloração. Numa amostra de 550 sementes tomadas ao acaso foram medidos o comprimento, a largura e a espessura. Considerou-se como comprimento, a 
medida compreendida entre a porção basal e a porção apical da semente.

A largura e a espessura foram medidas na porção intermediária, sendo que para a largura desconsideraram-se as porções alares das sementes. Os dados obtidos foram analisados por meio da distribuição de freqüência sendo os intervalos de classe estimados de acordo com Beiguelman (1991) e calculados a média $(X)$, a variância $\left(S^{2}\right)$ e o desviopadrão (S).

\section{Armazenamento e germinação das sementes}

As sementes foram obtidas de frutos em estádio inicial de deiscência. Para a avaliação do comportamento fisiológico, as sementes foram acondicionadas em sacos de papel (tipo kraft) e armazenadas em temperatura ambiente (sem controle de temperatura e umidade relativa), pelos períodos de 120, 480 e 720 dias. Transcorrido cada período de armazenamento, as sementes foram incubadas em germinadores sob 4 tratamentos: temperaturas constantes de 18,25 e $30^{\circ} \mathrm{C}$ em luz contínua, e sob temperatura alternada de $20-30^{\circ} \mathrm{C}$ com fotoperíodo de 12 horas. Os tratamentos foram arranjados em esquema fatorial $3 \times 4$ no delineamento experimental inteiramente casualizado com quatro repetições contendo 16 sementes.

Para os testes de germinação foram acondicionadas 16 sementes por gerbox contendo duas folhas de papel filtro como substrato. $O$ umedecimento foi realizado sobre o papel filtro com o auxílio de pipeta. Utilizou-se inicialmente o volume de $2 \mathrm{~mL}$ de água por gerbox. Foram realizadas contagens das sementes germinadas em dias alternados a partir do $4^{\circ}$ até o $32^{\circ}$ dia de implantação do teste. Os resultados foram expressos em porcentagem de germinação e índice de velocidade de germinação, de acordo com Popinigis (1985).

A determinação da umidade nas sementes armazenadas por 120, 480 e 720 dias foi feita em 200 sementes por período de armazenamento sendo divididas em quatro amostras de 50 sementes/repetição. Utilizou-se o método da estufa a $105^{\circ} \mathrm{C} \pm 3^{\circ} \mathrm{C}$ por 24 horas (BRASIL, 1992) sendo aplicada a fórmula $\% \mathrm{U}=[(\mathrm{Pi}-\mathrm{Pf}) / \mathrm{Pi}] \times 100$, onde $\mathrm{Pi}=\mathrm{Peso}$ inicial (em gramas) e $\mathrm{Pf}=\mathrm{Peso}$ final (em gramas). Os resultados foram expressos em porcentagem de teor de água.

Para efeito de análise estatística os dados originais sobre germinação foram transformados em arc sen $\sqrt{x / 100}$ e submetidos à análise de variância. Da mesma forma, os dados de Pi, Pf e teor de água tiveram as médias comparadas pelo teste de Tukey a $5 \%$ de probabilidade. As figuras e tabelas expressam os dados originais.

\section{RESULTADO E DISCUSSÃO}

\section{Morfometria dos frutos e sementes}

Os frutos da carobinha são cápsulas secas (Figura 1), de formato oblongo-obovada a orbicular, com deiscência loculicida perpendicular ao eixo seminífero, contendo epicarpo de cor marrom (quando completamente maduro), mesocarpo seco, pouco espesso e revestido por endocarpo de cor amarelo-opaca. Na porção mediana dos lóculos está presente uma estrutura mediana proeminente (coluna) formada, provavelmente, a partir do desenvolvimento das placentas (Barroso et al., 1999). Esta estrutura é de coloração branca e serve de apoio à disposição das sementes, ocorrendo paralelamente ao plano de deiscência da cápsula.

As sementes apresentam formato cordiforme a orbicular, com expansões aladas bilaterais e simétricas (Figura 1), em continuidade com tegumento membranáceo de coloração castanha, variando em tons de claro a escuro e adaptadas à dispersão anemocórica. As sementes estão dispostas em camadas sobre a coluna central e presas pelo hilo (Barroso et al., 1999; Souza, 2003) e ocorrem em número variado, desde 9 a 62 sementes por fruto.

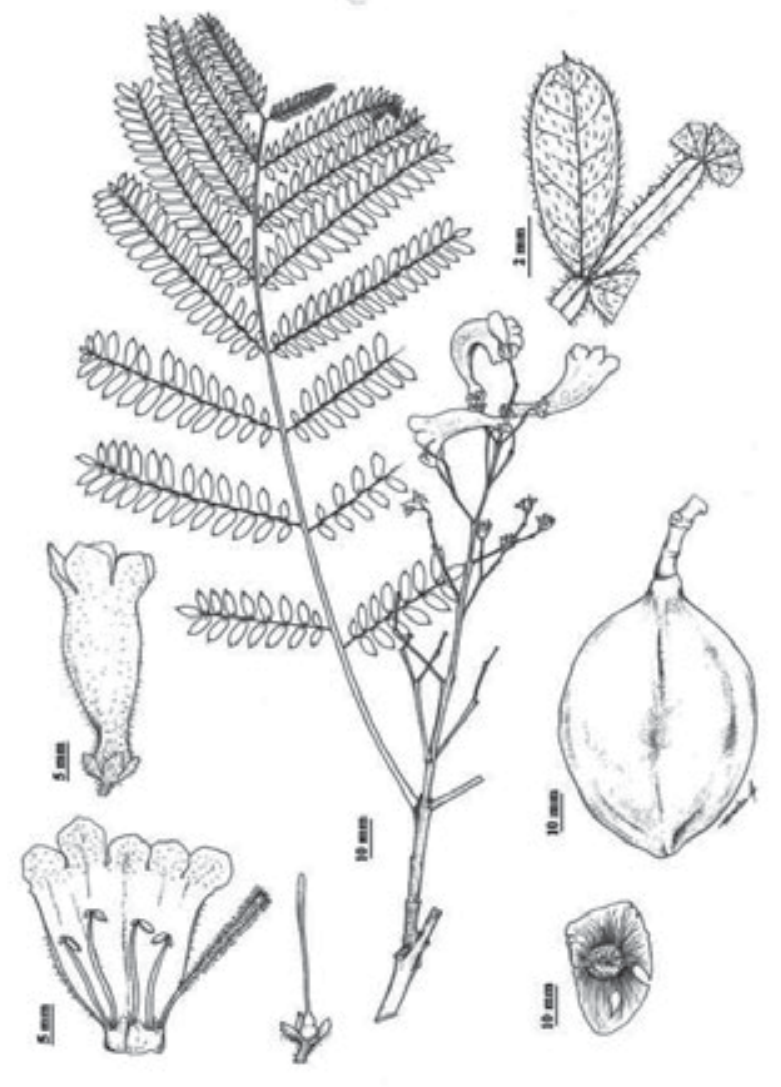

FIGURA 1. Características morfológicas das folhas, flores, frutos e sementes de J. decurrens subsp. symmetrifoliolata. 
Os frutos da carobinha apresentaram distribuição de frequência assimétrica com grande variabilidade quantitativa nas características, tais como a massa, o comprimento, a largura, a espessura e o número de sementes por fruto.

A frequência relativa da massa dos frutos
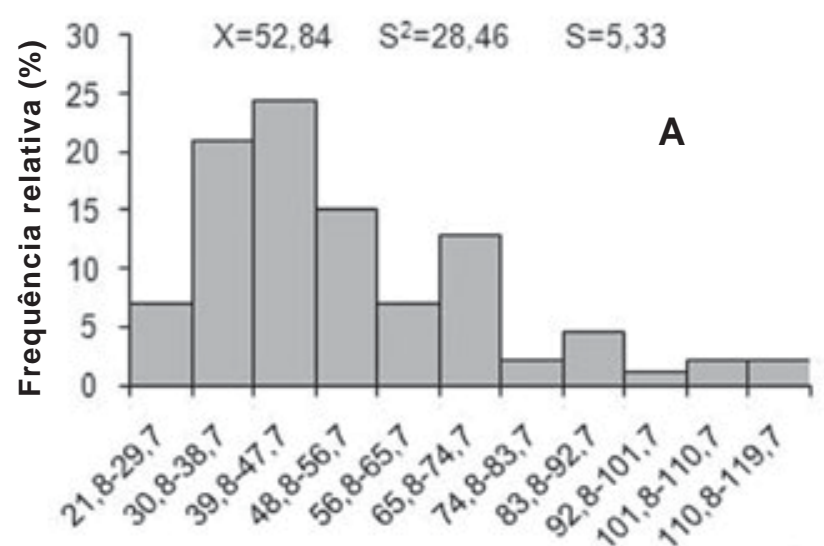

Massa dos frutos (g)

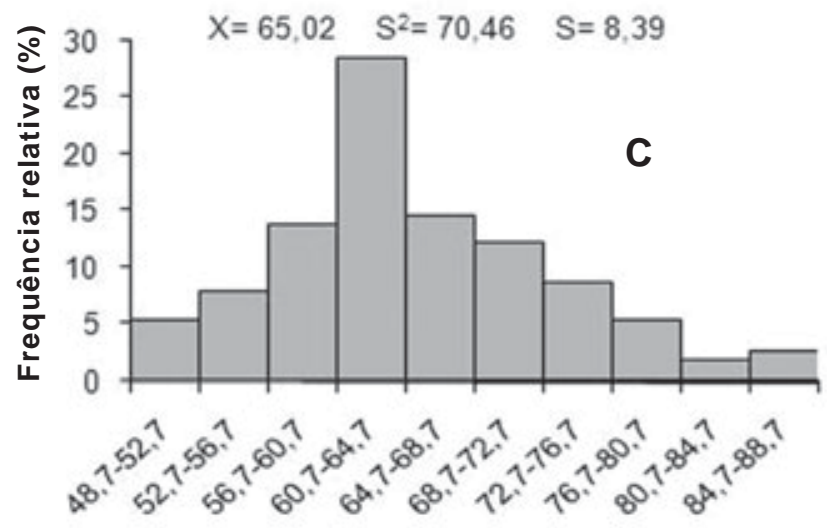

Largura dos frutos $(\mathrm{mm})$ apresentou distribuição assimétrica com variação entre $21,8 \mathrm{~g}$ a 119,7 g (Figura 2A), sendo a maior classe para os frutos com massa entre 39,8 a 47,7 g (24,4\%). A massa média de 50 sementes, considerando as formações alares, foi de $1,6 \mathrm{~g}$ e o número médio estimado
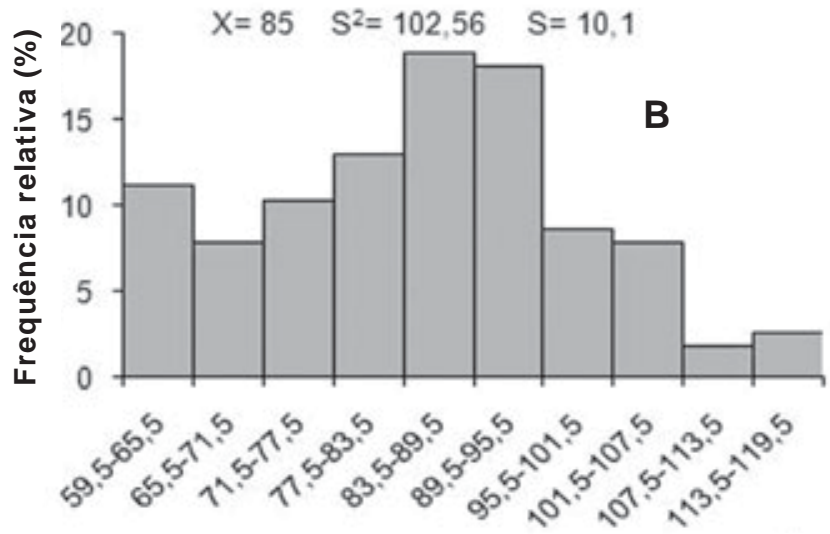

Comprimento dos frutos $(\mathrm{mm})$
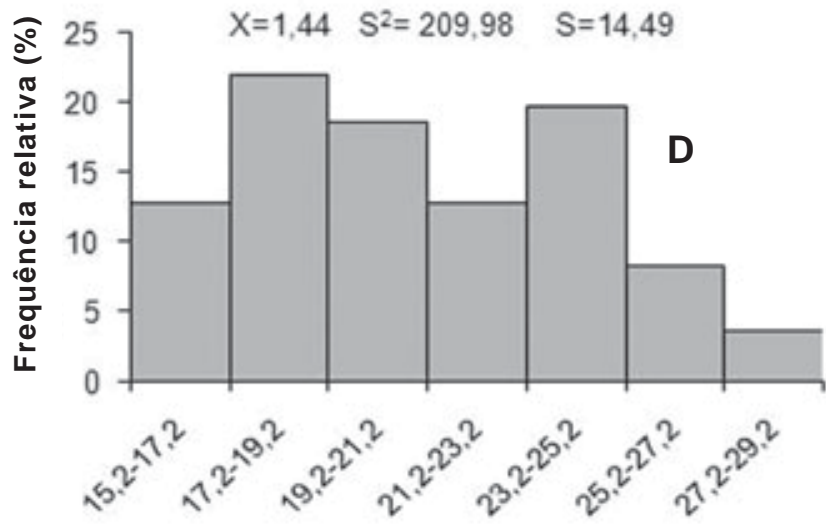

Espessura dos frutos (mm)

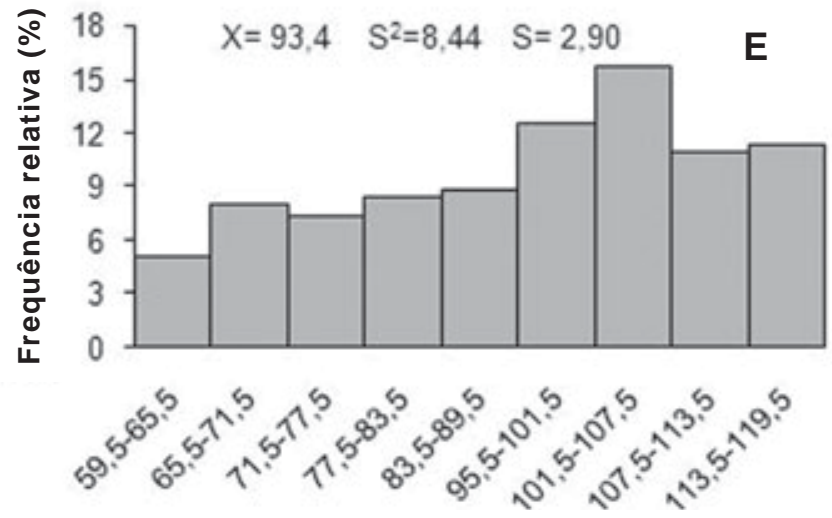

Número de sementes/comprimento dos frutos

FIGURA 2. Frequências relativas das características morfométricas (massa, comprimento, largura, espessura e número de sementes/fruto) de frutos de carobinha (J. decurrens subsp. symmetrifoliolata). Dourados, MS, UFGD, 2008. 
de sementes por kilograma foi de 31.545 unidades, demonstrando que estas são extremamente leves, facilitando o processo de dispersão por anemocoria. Para Jacaranda copaia D. Don, Vieira et al. (2004) registraram 12.269 sementes por kilograma, sendo a diferença em razão de as sementes serem maiores, chegando a $12 \mathrm{~mm}$ de comprimento e $20 \mathrm{~mm}$ de largura.

O comprimento dos frutos variou de 59,5 a $119,5 \mathrm{~mm}$ (Figura 2B) sendo as maiores frequências entre 83,5 e $89,5 \mathrm{~mm}(19,9 \%)$. A largura dos frutos variou de 48,7 a 88,7 mm (Figura $2 \mathrm{C})$ sendo a maior frequência com valores entre 60,7 a $64,7 \mathrm{~mm}(28,4 \%)$. A espessura dos frutos variou de 15,2 a 29,2 $\mathrm{mm}$ (Figura 2D), com as maiores frequências dentro dos limites de 17,2 a 19,2 mm $(22,0 \%)$.

A variação entre classes de frequência foi menor quando analisado o número de sementes por classe de comprimento dos frutos, sendo registrado o maior número de sementes nos frutos que apresentaram entre 101,5 a $107,5 \mathrm{~mm}$ de comprimento (15,8\%). O número médio de sementes por fruto foi de 31 unidades, mas observou-se tendência de aumento no número de sementes nos frutos maiores, com ligeira queda para as duas últimas classes. Dessa forma, pode-se inferir que a quantidade de sementes é dependente do tamanho dos frutos (Figura 2E).

Analisando as medidas de comprimento das sementes, constatou-se que houve variações de 5,9 a 13,0 mm (Figura 3A), sendo as maiores entre 8,8 e $9,5 \mathrm{~mm}(23,9 \%)$. Para a largura das sementes, encontrou-se variação de $6,0 \mathrm{~mm}$ a $12,0 \mathrm{~mm}$ (Figura 3B), sendo a maior frequência entre os valores 8,4 a $9,0 \mathrm{~mm}(18,6 \%)$. A espessura das sementes variou de 0,4 a 2,2 $\mathrm{mm}$ (Figura 3C), estando as maiores frequências dentro dos limites de 1,4 a $1,5 \mathrm{~mm}$ $(26,5 \%)$.

Os dados obtidos demonstram que em espécies não domesticadas, como é o caso de $J$. decurrens subsp. symmetrifoliolata, é comum ocorrer variações das características morfométricas, como também foi constatado em sementes de Tabebuia aurea (Silva Manso) Benth. \& Hook. F. ex. S. Moore,
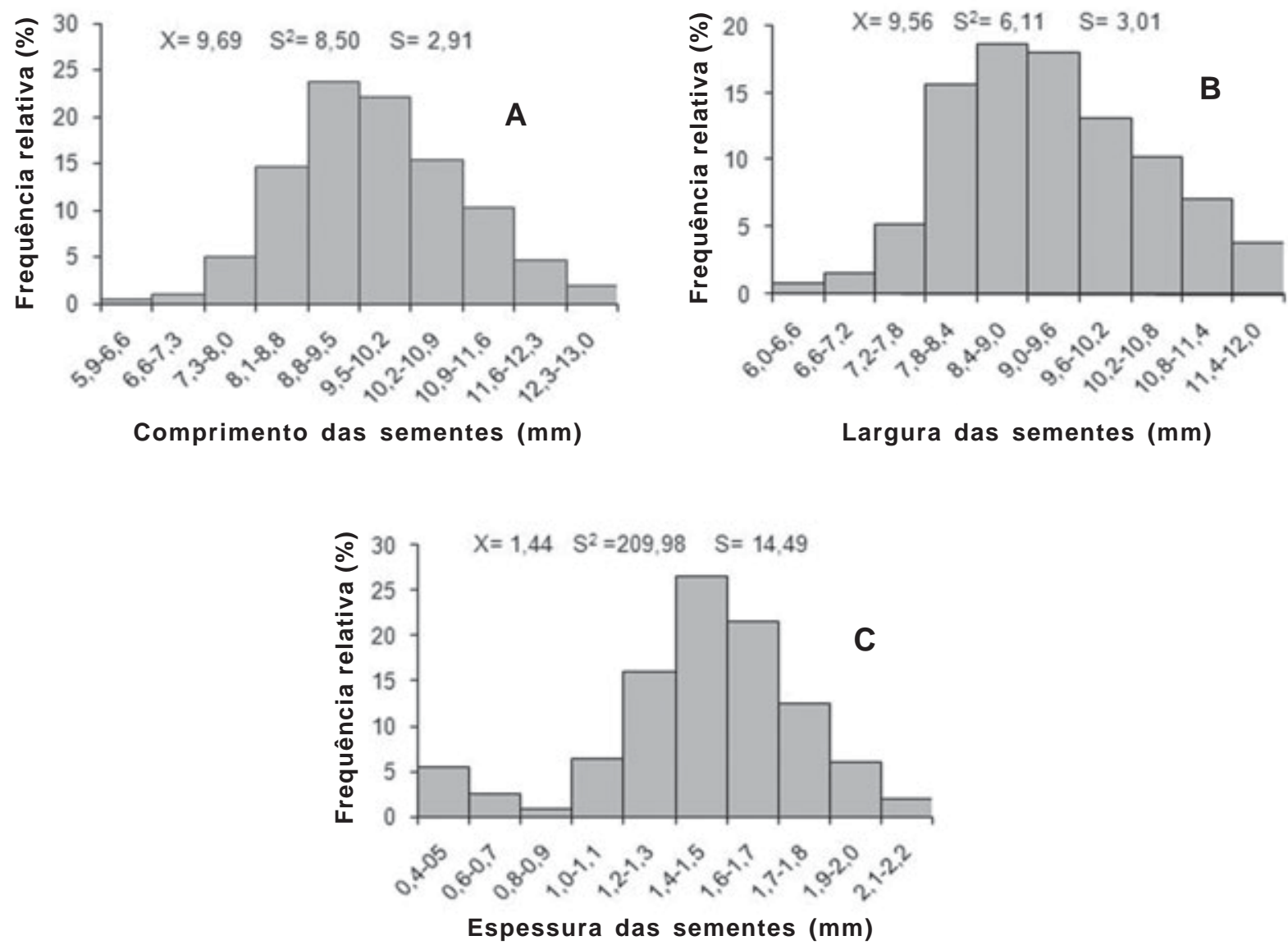

FIGURA 3. Frequências relativas das características morfométricas (comprimento, largura, e espessura) de sementes de carobinha (J. decurrens subsp. symmetrifoliolata). Dourados, MS, UFGD, 2008.

Rev. Bras. PI. Med., Botucatu, v.14, n.2, p.267-275, 2012. 
por Salomão \& Fujichima (2002) e por Oliveira et al. (2006), que registraram, respectivamente, $22,9 \mathrm{~mm}$ e $17,3 \mathrm{~mm}$ de comprimento e $17,3 \mathrm{~mm}$ e $13,3 \mathrm{~mm}$ de largura.

As variações nas medidas registradas nos frutos e sementes representam um indício da alta variabilidade genética populacional, visto que a reprodução de J. decurrens subsp. symmetrifoliolata ocorre por alogamia, conforme constatado por Buranello (2006).

\section{Armazenamento e germinação das sementes}

A porcentagem de germinação e o índice de velocidade de germinação (IVG) das sementes foram influenciados significativamente pelo período de armazenamento. As sementes de carobinha puderam ser armazenadas por 120 dias sob temperatura ambiente e apresentaram índices de germinação variáveis, dependendo da temperatura a que foram submetidas durante o teste de germinação.

A germinação das sementes armazenadas por 120 dias e submetidas à temperatura de $25^{\circ} \mathrm{C}$ iniciou-se aos cinco dias após a semeadura e chegou a 69,4\% após 32 dias do início do teste, tendo IVG de 0,983 . Quando o teste de germinação foi conduzido sob temperatura de $30^{\circ} \mathrm{C}$ constante com luz e, em outra condição, sob temperaturas alternadas de 20$30^{\circ} \mathrm{C}$ com 12 horas de luz, a germinação iniciou-se entre 10 e 13 dias, sendo a porcentagem de germinação de $63,9 \%$ e $63,8 \%$ e o IVG de 0,486 e 0,413 , respectivamente para tais condições do teste. Quando o teste foi conduzido a $18^{\circ} \mathrm{C}$, a germinação foi tardia e menor em relação aos demais tratamentos iniciando-se aos 21 dias e resultando em $27,7 \%$ de germinação e 0,119 de IVG (Tabela 1). As sementes armazenadas por 480 dias e 720 dias sob temperatura ambiente não germinaram em nenhuma das temperaturas testadas. No entanto, não foram realizados testes para saber se estavam mortas ou dormentes.

Em sementes recém-colhidas de $J$. decurrens subsp. symmetrifoliolata, obteve-se as maiores taxas de germinação quando o teste de germinação foi conduzido sob temperatura alternada (20-30ํㅡ), não diferindo, no entanto, das taxas de germinação registradas no teste sob temperatura constante de $25^{\circ} \mathrm{C}$. As porcentagens de germinação nestas condições foram $79,4 \%$ e $78,1 \%$, respectivamente. O teste de germinação conduzido a temperatura de $20^{\circ} \mathrm{C}$ resultou em porcentagem de germinação menor (67,2\%). Esse resultado confirma que, para essa subespécie, o poder germinativo das sementes vai diminuindo gradativamente fazendo-se importante conhecer as condições adequadas de armazenamento visando o controle das variações da temperatura e da umidade relativa do ar para aumentar a longevidade das sementes.

Além da baixa porcentagem de germinação sob temperatura de $18^{\circ} \mathrm{C}$ esta condição interferiu no desenvolvimento das plântulas cessando o crescimento após a emissão da radícula. Esses resultados evidenciam que a germinação de sementes de J. decurrens subsp. symmetrifoliolata é afetada quando submetidas a temperaturas baixas. De acordo com Carvalho \& Nakagawa (1988), baixas temperaturas promovem germinação mais lenta em espécies tropicais pois o processo germinativo envolve enzimas cuja atividade máxima é geralmente acima de $25^{\circ} \mathrm{C}$. Sendo assim, temperaturas inferiores ou superiores à ótima, tendem a reduzir a velocidade do processo germinativo, expondo as plântulas por maior período a fatores adversos.

A redução gradativa da temperatura pode também exercer efeitos negativos sobre a velocidade de embebição e de mobilização de reservas, provocando decréscimo acentuado na velocidade de germinação (Marcos Filho, 2005) pelo fato da atividade fisiológica do embrião ser influenciada pela quantidade de oxigênio, água disponível e pela temperatura (Melo \& Eira, 1995b), tal como pode ter ocorrido com a espécie em questão.

Foi observada diferença significativa no peso das sementes durante o armazenamento; e mesmo não havendo diferença em relação ao peso inicial e

TABELA 1. Porcentagem e índice de velocidade de germinação de sementes de J. decurrens subsp. symmetrifoliolata em função da temperatura de germinação, após armazenamento por 120 dias. Dourados, MS, UFGD, 2008.

\begin{tabular}{ccc}
\hline $\begin{array}{c}\text { Temperaturas no germinador } \\
\text { C }\end{array}$ & \multicolumn{2}{c}{ 120 dias de armazenamento } \\
\% Germinação & IVG \\
\hline 18 & $27,7 \mathrm{~b}$ & $0,119 \mathrm{~b}$ \\
25 & $69,4 \mathrm{a}$ & $0,983 \mathrm{a}$ \\
30 & $63,8 \mathrm{a}$ & $0,486 \mathrm{a}$ \\
Alternada $20-30$ & $61,1 \mathrm{a}$ & $0,413 \mathrm{a}$ \\
\hline C.V.\% & 37,0 & 63,0 \\
\hline Médias seguidas pela mesma letra nas colunas não diferem entre si por Tukey a 5\% de probabilidade.
\end{tabular}

Rev. Bras. PI. Med., Botucatu, v.14, n.2, p.267-275, 2012. 
porcentagem de teor de água nas sementes de $J$. decurrens subsp. Symmetrifoliolata a observa-se a diminuição da água das sementes ocrrendo gradativamente com o aumento do tempo de armazenamento (Tabela 2).

Deve-se considerar que as variações de temperatura e umidade relativa do ar no ambiente de armazenamento eram bastante acentuadas, com maiores variações durante o período diurno, com aumentos de temperatura e redução da umidade do ambiente. No período noturno, as temperaturas eram mais baixas e as umidades relativas do ar mais altas. Além disso, deve-se considerar a variação térmica entre os meses do ano (inverno e verão). Esses fatores, associados ao tipo de embalagem onde foram acondicionadas as sementes, contribuíram para a perda da viabilidade das sementes.
Os valores para porcentagem de teor de água registrado para J. decurrens subsp. symetrifoliolata nas três épocas de armazenamento à temperatura ambiente estão próximos do padrão proposto por Brasil (2003) para J. micrantha Cham., em que os teores de umidade variaram de 6,7 a $11,7 \%$. O fato de somente as sementes armazenadas por 120 dias terem germinado é um indicativo de que a espécie é tolerante à dessecação, ou seja, espécies que apresentam a capacidade de recuperar as funções biológicas após desidratação até o ponto em que não reste fase líquida nas células (Black et al., 2002). Entretanto, para manter a viabilidade germinativa é necessário que as sementes sejam armazenadas em ambientes com baixas temperaturas, como constatado em J. acutifolia Humb \& Bonpl., onde a redução no teor de umidade de $7,4 \%$ para $4,0 \%$ não influenciou

TABELA 2. Médias de peso inicial e final e porcentagem de teor de água em amostras de 50 sementes de $J$. decurrens subsp. symmetrifoliolata em três épocas de armazenamento. Dourados, MS, UFGD, 2008.

\begin{tabular}{cccc}
\hline Armazenamento & Peso inicial $(\mathbf{g})$ & Peso final $(\mathbf{g})$ & \% de teor de água \\
\hline 0 dia & $1,586 \mathrm{~b}$ & $1,467 \mathrm{~b}$ & $7,50 \mathrm{a}$ \\
120 dias & $1,336 \mathrm{~b}$ & $1,249 \mathrm{~b}$ & $6,60 \mathrm{a}$ \\
480 dias & $1,726 \mathrm{ab}$ & $1,626 \mathrm{a}$ & $5,88 \mathrm{a}$ \\
720 dias & $1,716 \mathrm{ab}$ & $1,620 \mathrm{a}$ & $\mathrm{a}$ \\
\hline C.V. $\%$ & 12,1 & 12,2 & 20,3 \\
\hline \multicolumn{2}{l}{ Médias seguidas pela mesma letra na coluna não diferem entre si por Tukey a 5\% de probabilidade. }
\end{tabular}

a qualidade fisiológica das sementes armazenadas em temperaturas subzero (Melo \& Eira, 1995b).

Analisando o comportamento fisiológico registrado para as sementes $J$. decurrens subsp. symmetrifoliolata, em função do período de armazenamento e teor de água das sementes, é possível classificá-la como ortodoxa ou intermediária, pois mesmo com baixos teores de água mantiveram o poder germinativo. Outros representantes de Bignoniaceae apresentam comportamento ortodoxo, tais como Jacaranda cuspidifolia Mart ex. DC. (Scalon et al., 2006), Jacaranda brasiliana (Lam.) Pers. (Salomão et al., 2003), Jacaranda copaia D. Don (Vieira et al., 2004), Jacaranda acutifolia (Mello \& Eira, 1995b), Tabebuia avellanedae Lorentz ex Griseb, Tabebuia ochraceae (Cham.) Standl., Tabebuia roseoalba (Ridl) Sand. (Mello \& Eira, 1995a), Tabebuia serratifolia (Vahl) Nich e Tabebuia chrysotricha (Mart.) ex DC. (Santos et al., 2005).

Embora muitas espécies de Bignoniaceae sejam ortodoxas (Medeiros \& Eira, 2006) ressaltam que não é possível afirmar a que grupo fisiológico determinada espécie classifica-se utilizando como base o comportamento fisiológico da família ou do gênero, pois na própria espécie podem ocorrer diferenças intra-específicas devido aos estágios de maturação das sementes, às condições de secagem que estas foram submetidas, à variabilidade genética ou ao ambiente em que foram obtidas.

Concluiu-se que os frutos e as sementes de J. decurrens subsp. symmetrifoliolata apresentam grande variabilidade em relação à massa, comprimento, largura e espessura. Em função de ter sido possível manter o poder germinativo das sementes armazenadas por até 120 dias em temperatura ambiente, e não nos armazenamentos mais longos de 480 e 720 dias, sugere-se que a carobinha seja classificada como espécie intermediária (entre ortodoxa e recalcitrante). Entretanto, faz-se necessário investigar em qual temperatura e umidade relativa do ar seria mais adequado para armazenar a semente da espécie por mais de 120 dias, sem que ocorra a perda da viabilidade germinativa, sendo esse um dos objetivos de nossas futuras pesquisas.

\section{AGRADECIMENTO}

À Fundação de Apoio ao Desenvolvimento do Ensino, Ciência e Tecnologia do Estado do Mato

Rev. Bras. PI. Med., Botucatu, v.14, n.2, p.267-275, 2012. 
Grosso do Sul (FUNDECT), pela bolsa de doutorado e apoio financeiro concedidos. À professora doutora Rosana Farias Singer, UNICAMP/SP, pela confirmação na identificação da espécie. A Reinaldo Pinto, UFV/ $M G$, pela elaboração da prancha apresentada neste trabalho.

\section{REFERÊNCIA}

AGUIAR, I.B.; PIÑA-RODRIGUES, M.B.; FIGLIOLA, M.B. Sementes florestais tropicais. Brasília:ABRATES, 1993. 350p.

BARROSO, G.M. et al. Frutos e sementes: morfologia aplicada à sistemática de dicotiledôneas. Viçosa: UFV, 1999. 443p.

BEIGUELMAN, B. Curso prático de bioestatística. 2.ed. Ribeirão Preto: Sociedade Brasileira de Genética. 1991. $231 \mathrm{p}$.

BELTRATI, C.M.; PAOLI, A.A.S. Sementes. In: APPEZZATO-DA-GLÓRIA, B.; CARMELLO-GUERREIRO, S.M. Anatomia vegetal. Viçosa: UFV, 2003. p.399-424. BLACK, M.; OBENDORF, R.L.; PRITCHARD, H.W. Damage and tolerance in retrospect and prospect. In: BLACK, M.; PRITCHARD, H.W. (Eds.). Desication and survival in plants: drying without dying. Wallingford: $\mathrm{CABI}$, 2002. p.367-82.

BRASIL. Legislação brasileira sobre sementes e mudas; Lei no 10.711, de 05 de agosto de 2003, Decreto no 5.153, de 23 de julho de 2003. Diário Oficial da União, Brasília, 06/08/2003, Seção 1, p.1.

BRASIL. Ministério da Agricultura e Reforma Agrária. Regras para análise de sementes. Brasília: Coordenação de Laboratório Vegetal - CLAV, Departamento Nacional de Defesa Vegetal, 1992. 365p.

BURANELLO, C.S. Biologia reprodutiva de Jacaranda decurrens subsp. symmetrifoliolata(Farias \& Proença)carobinha-do-campo. 2006. 14p. Trabalho de Conclusão de Curso (Graduação - Ciências Biológicas) Universidade Estadual de Mato Grosso do Sul, Dourados. CARVALHO, N.M.; NAKAGAWA, J. Sementes: ciência, tecnologia e produção. Campinas: Fundação Cargill, 1988. 424p.

CRUZ, D.F.; MARTINS, P.O.; CARVALHO, J.E.U. Biometria de frutos e sementes e germinação de jatobá-curuba (Hymenaea intermedia Ducke, LeguminosaeCaesalpinioideae). Revista Brasileira de Botânica, v.24, n.2, p.161-5, 2001.

FARIAS, R.; PROENÇA, C. Jacaranda decurrens subs. symmetrifoliolata FARIAS \& PROENÇA (Bignoniaceae), novo táxon para o bioma cerrado. Bradea. Boletim do Herbarium Bradeanum, v.11, n.2, p.5-9, 2003.

FERRONATO, A.; DIGNART, S.; CAMARGO, I.P. Caracterização das sementes e comparação de métodos para determinar o teor de água em sementes de sucupira-preta (Bowdichia virgilioides H.B.K. Papilionoideae) e pé-de-anta (Cybistax antisyphilitica Mart. - Bignoniaceae). Revista Brasileira de Sementes, v.22, n.2, p.206-14, 2000.

FLORIANO, E.P. Armazenamento de sementes florestais. Caderno didático, n.1, 1.ed. Santa Rosa: ANORGS, 2004. 10p.
IBGE- FUNDAÇÃO INSTITUTO BRASILEIRO DE GEOGRAFIA E ESTATÍSTICA. Manual técnico da vegetação brasileira. n.1, Rio de Janeiro, 1992. 92p. MARCOS FILHO, J. Fisiologia de sementes de plantas cultivadas. Piracicaba: FEALQ (Biblioteca de Ciências Agrárias Luiz de Queiroz, 12), 2005. 495p.

MEDEIROS, A.C.S.; EIRA, M.T.S. Comportamento fisiológico, secagem e armazenamento de sementes florestais nativas. Colombo: Embrapa, 2006. 14p. (Circular Técnica 127).

MELLO, C.M.C.; EIRA, M.T.S. Conservação de sementes de ipês (Tabebuia spp.). Revista Árvore, v.19, n.4, p.42732, 1995a.

MELLO, C.M.C.; EIRA, M.T.S. Conservação de sementes de jacarandá mimoso (Jacaranda acutifolia Humb \& Bonpl.)-Bignoniaceae. Revista Brasileira de Sementes, v.17, n.2, p.193-6, 1995b.

MELO, J.T. et al. Coleta, propagação e desenvolvimento inicial de plantas do cerrado. In: SANO, S.M.; ALMEIDA, S.P.; RIBEIRO, J.F. Cerrado: ecologia e flora. v.1, Brasília: Embrapa Cerrados/Embrapa Informação Tecnológica, 2008. p.321-50.

NUNES, G.P. et al. Plantas medicinais comercializadas por raizeiros no Centro de Campo Grande, Mato Grosso do Sul. Revista Brasileira de Farmacognosia [online], v.13, n.2, p.83-92, 2003. Disponível em: <http://dx.doi.org/ 10.1590/S0102-695X2003000200004>. Acesso em: 19 mar. 2008.

OLIVEIRA, A.K.M.; SCHLEDER, E.D.; FÁVERO, S. Caracterização morfológica, viabilidade e vigor de sementes de Tabebuia aurea (Silva Manso) Benth. \& Hook. f. ex. S. Moore. Revista Árvore, v.30, n.1, p.25-32, 2006.

PÉREZ, D. Etnobotánica medicinal y biocidas para Malaria en la región Ucayali. Folia Amazónica, v.13, n.12, p.87-108, 2002.

POPINIGIS, F. Fisiologia da semente. 2.ed. Brasília: ABRATES, 1985. 298p.

POTT, A.; POTT, V.J. Plantas do pantanal. Corumbá: EMBRAPA- SPI, 1994, 320p.

RODRIGUES, V.E.G.; CARVALHO, D.A. Levantamento etnobotânico de plantas medicinais no domínio dos cerrados na região do Alto Rio Grande - Minas Gerais. Revista Brasileira de Plantas Medicinais, v.9, n.2, p.1735, 2007.

SALOMÃO, A.N. et al. Germinação de sementes e produção de mudas de plantas do Cerrado. Brasília: Rede de Sementes do Cerrado, 2003. 96p.

SALOMÃO, A.N.; FUJICHIMA, A.G. Resposta de sementes de Tabebuia aurea (Silva Manso) Benth. \& Hook. F. ex. S. Moore (Bignoniaceae) à dessecação e ao congelamento em temperaturas subzero. Brasília: Embrapa, 2002. 4p. (Circular Técnica 76).

SANGALLI, A.; VIEIRA, M.C.; ZÁRATE, N.A.H. Levantamento e caracterização de plantas medicinais nativas com propriedades medicinais em fragmentos florestais e de cerrado, em Dourados-MS, numa visão etnobotânica. Acta Horticulturae, n.569, p.173-84, 2002. SANGALLI, A.; SCALON, S.P.Q.; VIEIRA, M.C. Cor, temperatura e pré-embebição na germinação de sementes de carobinha (Jacaranda decurres sub. symmetrifoliolata Farias \& Proença) Bignoniaceae. Revista Brasileira de Plantas Medicinais, v.7, n.1, p.7985, 2004. 
SANTOS, D.L.; SUGAHARA, V.Y.; TAKAKI, M. Efeitos da luz e da temperatura na germinação de sementes de Tabebuia serratifolia (Vahl) Nich, Tabebuia chrysotricha (Mart. ex DC.) Standl. e Tabebuia roseo-alba (Ridl) Sand Bignoniaceae. Ciência Florestal, v.15, n.1, p.87-92, 2005. SCALON, S.P.Q. et al. Armazenamento e tratamentos prégerminativos em sementes de jacarandá (Jacaranda cuspidifolia) Mart. Revista Árvore, v.30, n.2, p.179-85, 2006. SCHWENK, L.M.; SILVA, C.J. A etnobotânica da Morraria Mimoso no Pantanal de Mato Grosso. In: SIMPÓSIO SOBRE RECURSOS NATURAIS E SÓCIOECONÔMICOS DO PANTANAL, 3., 2000, Corumbá. Anais... Corumbá: Embrapa, 2000. p.1-27.
SOUZA, L.A. Morfologia e anatomia vegetal: células, tecidos, órgãos e plântulas. Ponta Grossa: Editora UEPG, 2003. 259p.

VIEIRA, A.H. et al. Silvicultura de espécies florestais em Rondônia. Rondônia: CPAFRO-Embrapa. Base de Dados. 2004. Disponível em: <http://www.cpafro. embrapa.br/embrapa/bases/parapara.htm>. Acesso em: 26 out. 2007.

VILA VERDE, G.M.; PAULA, J.R.; CANEIRO, D.M. Levantamento etnobotânico das plantas medicinais do cerrado utilizadas pela população de Mossâmedes (GO). Revista Brasileira de Farmacognosia, v.13, p.646, 2003. 